\title{
A comparative study of copper thin films deposited using magnetron sputtering and supercritical fluid deposition techniques
}

\author{
Giroire B.a,b, Ali Ahmad M.a,b, Aubert G.a,b, Teulé-Gay L.a,b, Michau D.a,b, Watkins J. J.c, Aymonier C.a,b, Poulon-Quintin \\ A..$^{a, b}$ \\ aCNRS, Univ Bordeaux, ICMCB, UPR 9048, F 33600 Pessac, France. \\ bUniv. Bordeaux, ICMCB, UPR 9048, F 33600 Pessac, France. \\ 'Department of Polymer Science and Engineering, University of Massachusetts Amherst, 120 Governors Drive, Amherst, MA 01003, United \\ States
}

\begin{abstract}
:
A comparison of crystallinity, microstructure, surface morphology and electrical conductivity is proposed for the deposition of copper films, using supercritical fluid chemical deposition (SFCD) and RF magnetron sputtering techniques. Both preparation methods yield nanocrystalline Cu films $(<100 \mathrm{~nm})$ but SFCD gives access to a higher crystallinity for the same AIN substrate temperature during the deposit. Based on the film characteristics, a comparison of the evolution of electrical properties is done for RF magnetron sputtered copper films and SFCD ones with $\mathrm{H}_{2}$ as reducing agent. Uniform strain values are significantly reduced when SFCD technique is used and crystallinity is highly increased leading to lower resistivity values for a same crystallite size. This study demonstrates the viability of the SFCD technique to produce high quality nanostructured copper thin films with low resistivity values.
\end{abstract}

\section{Introduction}

The study of metallic materials and metallization processes for planar device technology has taken on a new lease of life due to the rapid growth of wireless communications. Copper has been identified as the conducting material of choice for a long time for connections in integrated circuits with submicron features. Its low electrical resistivity, high thermal conductivity, high electromigration resistance, excellent chemical and thermodynamic characteristics and low coefficient of resistance [1-3] are the key properties in electronic applications. Nanocrystalline copper films acquire potential related to its original physical and chemical characteristics [4,5]. Beside the crystallite size for electronic devices, it was demonstrated that the microstructure (impurities, crystallographic texture...) also needs to be optimized to improve the electrical properties of the Cu films $[6,7]$.

Copper metallization processes conventionally used in industry are electroless deposition, electroplating and chemical vapor deposition (CVD). These processes are famous to be non-environmentally friendly due to the toxic wastewater and chemicals generated from the manufacturing and rinsing processes. Recently, environmentally friendly processes such as aerosol deposition (AD) [8] were proposed as alternatives to electrolyte and electroplating methods. Unfortunately, the presence of copper oxides is detrimental to the resistivity with values five to seven times larger than bulk copper $(1.67 \mu \Omega \cdot \mathrm{cm})[9]$.

Supercritical fluid chemical deposition (SFCD) process mainly developed with supercritical carbon dioxide $\left(\mathrm{scCO}_{2}\right)$ can also be an alternative method that enables the fabrication of nanostructured films in an environmentally friendly manner and from a scalable technology [10-14]. SCFD technique is a one-pot, multi-step process that involves, the dissolution of a metallic precursor in a supercritical fluid followed by a chemical reaction (i.e. reduction) at the surface of a heated substrate to initiate the nucleation and growth of the film on a substrate 
$[15,16]$. For instance, the chemical reduction of a metallic precursor in the reaction medium $\left(\mathrm{scCO}_{2}\right)$ required the use of a reducing agent such as hydrogen. The formation of the films occurs via adsorption or sorption of the metallic precursor on the substrate. Compared to gas or liquid phase processes, SCFD is a hybrid approach that combines advantages of CVD and liquid-phase deposition with a greater precursor concentration and an environmentally friendly process. Using $\mathrm{scCO}_{2}\left(\mathrm{~T}_{\mathrm{c}}=31^{\circ} \mathrm{C}, \mathrm{P}_{\mathrm{c}}=73.8 \times 10^{6} \mathrm{~Pa}\right)$ [11], no liquid waste is generated and no solvent residue is left on the substrate. Supercritical $\mathrm{CO}_{2}$ presents the ability to solubilize a wide range of metallic precursors (Acetylacetonate, 2,2,6,6-tetramethylheptane-3,5-dione, hexafluoroacetylacetone, 2,2,7-trimethyl-3,5octanedionate, diisobutyrylmethane, cyclopentadienyl, etc...) and enables the deposition at high precursor concentration necessary for growth of films. Fast rates of deposition, good surface coverage and superior gap-filling ability are obtained thanks to $\mathrm{scCO}_{2}$ transport properties such as high diffusivity, low viscosity and zero surface tension, which facilitate rapid mass transfer. Compared to CVD process, low vapor pressures of precursors, mass transfer limited kinetics and generation of thermo-mechanical stresses are no more drawbacks to produce high purity copper films thanks to SFCD process.

This paper aims to compare the characteristics of copper films prepared with RF magnetron sputtered, considered as the reference coating method, and with SFCD using a cold wall-reactor. Microstructure and electrical properties of $\mathrm{Cu}$ films on AIN nonconductive substrates from both preparation techniques are discussed. The evolution of electrical properties with various copper metallization processes conventionally used in industry or recently developed is also presented as a function of the crystallites size (lower than $100 \mathrm{~nm}$ ) based on literature data.

\section{Experimental details}

All SFCD experiments were carried out in a stainless steel high pressure cold-wall reactor of $153 \mathrm{~mL}$ of internal volume operating in batch mode, as described by Hunde et al. [17]. A resistively heated stage was placed in the center of the vessel. A separated temperature control of the wall and the pedestal heater was insured to promote the deposition process. The reactor walls were kept at a lower temperature, at which the precursors do not decompose. Wall, substrate and reaction medium temperatures were controlled throughout the process with thermocouples. The decomposition only occurs on the AIN mirror polished and polycrystalline substrates (NEYCO), material being selected based on its properties like electrical insulation (resistivity $\geq 10^{6} \mathrm{M} \Omega \cdot \mathrm{m}$ at room temperature) and excellent thermal conductivity $\left(\geq 170 \mathrm{~W} \cdot \mathrm{m}^{-1} \cdot \mathrm{K}^{-1}\right.$ at room temperature). Prior to the deposition, the substrates were cleaned with isopropanol. Copper films deposited using SFCD were prepared from Bis(2,2,6,6tetramethyl-3,5-heptanedionato) copper (II) [Cu(tmhd) 2 ] $(99 \%$, Strem Chemicals) solid precursor (powder) used as received. The reaction medium was carbon dioxide $\left(99.9 \%\right.$, Air Liquide). A carbon dioxide-hydrogen mixture $\left(\mathrm{CO}_{2} / \mathrm{H}_{2}\right.$ - 99.99\%, Air Liquide) with a molar ratio $0.2 / 0.8$ of $\mathrm{H}_{2} / \mathrm{CO}_{2}$ was also added to the reaction medium to reduce the copper precursor. All chemicals were used without further purification.

The cleaned substrate was placed on a pedestal heater. The copper precursor was put in the reactor all around the substrate. The chamber was then sealed and flushed with high purity nitrogen. After the purge, the $\mathrm{CO}_{2} / \mathrm{H}_{2}$ mixture

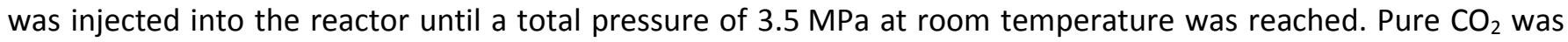
then added to increase pressure until $5 \mathrm{MPa}$. The wall and substrate were heated to 40 and $100{ }^{\circ} \mathrm{C}$, respectively, inducing an increase of pressure up to $6.8 \mathrm{MPa}$. Then, an additional $\mathrm{CO}_{2}$ injection was performed to reach supercritical conditions. Once the temperature and pressure were stabilized, a $10 \mathrm{~min}$ dissolution step was maintained to ensure a complete dissolution of the precursor in the reaction media. Temperatures were then set to the desired conditions i.e. 100 and $250^{\circ} \mathrm{C}$ for the wall and the substrate, respectively. The deposition reaction was performed during $90 \mathrm{~min}$. During the deposition process, a temperature difference of at least $150{ }^{\circ} \mathrm{C}$ was maintained between the wall and the stage throughout the reaction to promote the heterogeneous nucleation and film growth on the substrate. After cooling, depressurization and reactor flushing with $\mathrm{CO}_{2}$, the samples were recovered from the stage and named SFCD-250. Some of them were annealed at $400^{\circ} \mathrm{C}$ for $1 \mathrm{~h}$ under helium atmosphere and named SFCD-400.

Copper reference samples without nitrogen, carbon and oxygen contamination (already observed by Boo et al. [18] on Si (100) and glass substrates) were deposited on cleaned AIN substrates using RF magnetron sputtering technique (PM400, Plassys equipped with $51 \mathrm{~mm}$ in diameter target). A copper target (99.99\%, Neyco) was used. 
Before deposition, a cleaning procedure was completed by in situ ion etching (- $379 \mathrm{~V}$ for 3 min under $\operatorname{Ar} 99.99 \%$ purity; pressure maintained at $0.69 \mathrm{~Pa}$ ). The base pressure was $53 \mu \mathrm{Pa}$. The working pressure during the deposition process was $1 \mathrm{~Pa}$. The distance from the magnetron source to the substrate was fixed at $70 \mathrm{~mm}$. The deposition rate was selected at $10 \mathrm{~nm} / \mathrm{min}$ and the deposit was performed with additional heating of substrates at $250{ }^{\circ} \mathrm{C}$ (samples named PVD-250) and $400{ }^{\circ} \mathrm{C}$ (samples named PVD-400).

The surface morphology and thickness of the films were observed with a Jeol JMS 6360A scanning electron microscope (SEM) equipped with an energy dispersive X-ray spectrometer (EDS). For all the samples, the thickness was around $550 \mathrm{~nm}$.

X-ray diffraction (XRD) experiments were carried out on a PANalitycal X'pert MPD-PRO Bragg-Brentano $\theta-\theta$ geometry powder diffractometer with $\mathrm{Cu} \mathrm{K}_{\alpha 1}$ radiation $(\lambda=0.15406 \mathrm{~nm})$. The XRD instrument resolution was $0.05^{\circ}$.

The average surface roughness $\left(R_{a}\right)$ and highest peak to lowest valley distance $\left(R_{t}\right)$ of the samples were determined using Dektak 6M surface profilometer.

The electrical resistivity $\rho$ of continuous copper films was measured at room temperature using the 4-point probe method (Minirosion LTD type B model with the Wenner configuration i.e. the four electrodes are equidistant and collinear and the inner electrodes are used to measure voltage). The formula used is for a thin conductor film when probe spacing is much greater than the thickness of the conductor and considering an infinite thin film:

$$
\rho=\mathrm{e} \cdot(\pi / \ln (2)) \cdot \mathrm{U} / \mathrm{I}
$$

with e the film thickness, $U$ the potential difference and I the intensity.

\section{Results and discussion}

\subsection{Texture properties}

Fig. 1 shows the XRD patterns of the AIN substrate (JCPDS 00-025-1133), SFCD and magnetron sputtered deposited Cu films. XRD patterns are all in agreement with the face-centered-cubic (fcc) structure ICDD 01-085-1326 standard data. For fcc films, the close-packed (111) crystal surface has a relatively low surface free energy and is the most stable configuration [19] whereas the (220) plane exhibits the lowest plastic strain energy [20]. Quantitative information concerning the preferential crystallite orientation can be obtained from the texture $\mathrm{TC}_{\mathrm{hkl}}$ defined as follow [21]:

$\mathrm{TC}_{\mathrm{hkl}}=\frac{\mathrm{I}_{(\mathrm{hkl})} / \mathrm{I}_{0(\mathrm{hkl})}}{\sum_{\mathrm{i}=1}^{\mathrm{n}} \mathrm{I}_{(\mathrm{hkl})} / \mathrm{I}_{0(\mathrm{hkl})}}$

where $\mathrm{I}_{(\mathrm{hkl})}$ is the measured relative intensity of a plane (hkl) and $\mathrm{I}_{\mathrm{O}(\mathrm{hkl})}$ is the standard intensity of the plane (hkl) taken from ICDD 01-085-1326 standard data. In our case, the value $\mathrm{TC}_{\mathrm{hkl}}=1 / \mathrm{n}=1 / 3$ as 3 planes are included in our XRD patters and represents films with randomly oriented crystallites. Higher values correspond to the abundance of grains oriented in a given (hkl) direction [21].

In this study, all patterns retain mixed crystalline orientation of (111), (200), (220) planes (43.3, 50.6 and $73.1^{\circ}$, respectively). The other peaks correspond to the AIN substrate. Based on the analysis of the evolution of the peak intensity ratios $\left(I_{(111)} / I_{(200)}\right.$ and $I_{(111)} / I_{(220)}$, Fig. 1$)$ and the TC values $\left(\mathrm{TC}_{(111)}, \mathrm{TC}_{(200)}\right.$ and $\left.\mathrm{TC}_{(220)}\right)$, it can be concluded that (111) is the preferred orientation. Similar observations were already noticed in literature on films prepared from SFCD with alcohols or hydrogen as reducing agent [22], sputtered [5,18,23,24], metal vapor vacuum arc, ion 
implantation and ion beam assistant deposition technologies [25], aerosol deposition [8], pulse electroplating [26], electrodeposited [27] and CVD [28] on various substrates. An increase of the $\mathrm{I}_{(111)} / \mathrm{I}_{(200)}$ ratio (value equal to 2.17 if intensities are taken from ICDD 01-085-1326 standard data) and values superior to 0.33 are noticed when the substrate temperature increases or after annealing for SCFD films. Both procedures improve the thermodynamic stability of the film. This observation has already been noticed by Mukherjee et al. [5] after the annealing of nanocrystalline films prepared with DC magnetron sputtering and anodic vacuum arc. During the annealing of SCFD samples, a recrystallization of the amorphous copper could occur and could lead to the (111) crystallites growth. During magnetron sputtering experiments, a similar phenomenon could be observed thanks to the increase of adatom mobility with higher substrate temperatures.

No peak corresponding to oxide species such as $\mathrm{CuO}$ or $\mathrm{Cu}_{2} \mathrm{O}$ have been detected. Whatever the deposition technique, XRD analyses only confirmed the presence of metal copper. These results are in agreement with the literature for the both techniques. Using SIMS analyses, Cabanas et al. [22] have quantified a carbon and oxygen content lower than 0.1 at.\% in SCFD films ( $\mathrm{scCO}_{2}$ and ethanol or hydrogen as reducing agent). Optimized process parameters for magnetron sputtering (reduced base pressure, limitation of $\mathrm{O}^{+}$and ions generated in the magnetron discharge able to react with metallic atoms, target power, deposition rate...) also helps to reduce oxygen and nitrogen contamination in films $[5,18,29]$.

\subsection{Structural properties}

Table 1 presents the film thickness and the average crystallite size. Broadening and thinning of XRD peaks are related to the variation of the coherently diffracting domain sizes considerate as the crystallite size. Experimental diffraction patterns were fitted using the Le Bail method via Fullprof suite software taking into account the instrumental resolution function of the apparatus used in this study. However it was difficult to make specific conclusions about the crystallite size without taking into account the hypothesis that the broadening was more related to small crystallite size than strains in order to calculate the average crystallite size from the (111) copper Bragg peak using the Scherrer equation [30]. It can be observed that both SFCD and PVD copper films exhibit nanosized crystallites. An increase in average crystallite size with increasing substrate temperature is observed on samples prepared with the magnetron sputtering technique, behavior already reported in the literature for asdeposited [31] copper films. Similar behavior was observed after annealing on SFCD samples, behavior already reported in the literature for magnetron sputtered post-annealed [5] copper films.

However, sharper and narrower peaks are observed for PVD-400, SFCD-250 and SFCD-400 samples, which could indicate a higher degree of crystallinity comparing to PVD-250. The degree of crystallinity $X_{c}$ can be estimated following the method of Nara and Komiya from XRD analyses [32]. $X_{c}$ is the integrated intensity of crystalline peaks divided by the sum of the integrated intensities of the background and the crystalline peaks on the XRD patterns. Using this approach, it can be estimated that SFCD films possess a higher degree of crystallinity than the magnetron sputtered. An improved degree of crystallinity with substrate temperature is confirmed for magnetron sputtered samples, which has to be correlated with an increase of the adatoms mobility along the substrate surface. A similar effect is noticed when SFCD samples are annealed. The highest value is obtained for the SFCD-400 highlighting the benefic effect of annealing. Mukherjee et al. [5] also noticed an increase in degree of crystallinity of nanosized copper films upon annealing regardless of the deposition technique (sputtering or anodic vacuum arc plasma deposition techniques). Compared to the study of Mukherjee et al. [5], for similar crystallite sizes and higher film thicknesses, values obtained for sputtered samples in this study are two times lower. This can be explained by the different process parameters used (biased substrates, deposition rate, substrate distance...) and the increase of the thickness.

\subsection{Film strain}

Variations in lattice parameter a are observed when calculated with respect to the (111) plane. Uniform strain measurements $\varepsilon\left(\varepsilon=\left(d-d_{0}\right) / d_{0}\right)$ in the film are done using the theoretical unstressed $d_{0}$ and stressed $d$ lattice spacing determinate using (111) plane peak position on XRD patterns. Variations in lattice parameter a and strain $\varepsilon$ are presented in Table 2. Calculated lattice parameters are lower than the $3.615 \AA$ announced in the ICDD 01-085- 
1326 file. Negative strain values are obtained, suggesting the generation of tensile stresses when AIN substrate is used. The stress behavior in thin films depends on primarily the deposition process and on the substrate. Three main parts according to the instant of their generation composed the macroscopic elastic strains: 1) from epitactic or structural misfit between the film and the substrate, 2) the growing process itself and 3 ) the consequence of the cooling process after deposition. The contribution coming from the structural misfit between the copper film and the substrate is negligible because it can be easily relaxed by misfit dislocation networks at the interface. Cooling stresses commonly attributed to the different thermal expansion coefficients of the layer and the substrate. For copper layer, relaxation by plastic deformation occurs leading to a negligible contribution. So the stress should be caused by defects in the film and therefore dependent on the deposition process. Tensile stress in a film is generated at the crystallite boundaries, stretching the film in plane and contracting the film in the normal direction [5]. Stress are generated by different type of defects in the volume of the grown layer (substitution of atoms, displacement to interstitial sites, dislocations, vacancies...), caused by ion- or atom peening in sputtering and are increased with Ar sputtering pressure [5] or by heterogeneous nucleation and crystallite growth during the SFCD process.

Another interesting finding is that the strain values obtained with SFCD technique are significantly lower than for magnetron sputtering (around 3 times lower). No significant variation occurred when the substrate temperature was increased during magnetron sputtering deposit even if value is slightly increased. However, sample SFCD-400, which has been annealed at $400{ }^{\circ} \mathrm{C}$, seems to be almost unstressed.

Considering a specific volume, the smaller and the more uniform the grain size distribution is, the more evenly distributed the strain energy will be during annealing. Then, the internal stress distribution could be more even which could make the (220) grain with minimization strain energy grown easily and quickly. Du et al. [33] noticed a change in preferred orientation after annealing from (111) to (220). They explained this phenomenon by the effect of yield in (220) grain starting before the (111) grains. It was then concluded that this yielding process leads to strain energy minimization and explained the faster growth of the oriented grain (220). In our case, (111) is still the preferred orientation after annealing (SFCD-400). Therefore, $\varepsilon$ variation can only be explained by the (111) grains yielding happening (not the main phenomenon) and the (111) crystallite growth during recrystallization of amorphous copper.

\subsection{Surface morphology and microstructure}

Mech et al. [23] investigated the effect of DC magnetron sputtered copper film's thickness on the resistivity of thin films. Conducted studies showed that the bulk resistivity for films thicker than $250 \mathrm{~nm}$ were constant $(1.87 \mu \Omega \cdot \mathrm{cm})$ even if grain size increased with sputtering time. In this study, for all the type of sample, thickness was selected around $550 \mathrm{~nm}$ (Table 1).

The surface morphology of the SFCD-250 and PVD-400 films is shown in Fig. 2 (SEM micrographs). A columnar surface morphology and similar morphology of grains can be observed even if grain size seems to be different. Less defined grain boundaries are observed on samples prepared via SFCD technique, but grain sizes seem to be smaller (same tendency than crystallite size). For both methods, films present a regular surface coverage crack-free but a small porosity (in dark) could be detected. High film densities in direct contact with the substrate can be confirmed from cross-section observations (Fig. 2). No delamination can be observed. Quantification of the surface roughness (average surface roughness $R_{a}$ and total height of the roughness profile $R_{t}$ ) for both samples is presented in Table 3. It is well known for sputtering techniques that substrate temperature plays a key role in controlling the film growth process, leading to modification in surface smoothness [33-35] and change in film structure, specifically grain growth. Chan et al. [36] demonstrated an increase of the root mean square roughness Rq and lateral feature size of films of $500 \mathrm{~nm}$ thick films when the substrate temperature varied from 25 to $250{ }^{\circ} \mathrm{C}$. This behavior is associated to the increase in adatoms mobility and surface diffusion. In this study, a roughness increase is also observed when the substrate temperature increased from 250 to $400{ }^{\circ} \mathrm{C}$. Compared to magnetron sputtered samples, the SFCD-250 and SFCD-400 films exhibit lowest $R_{a}$ and $R_{t}$ values. This can be attributed to change in the nucleation and growth mechanisms of copper grains on the AIN substrate in correlation with the deposition technique. 


\subsection{Electrical resistivity}

Conductivity and resistivity measurements of copper films are presented in Table 4. It is obvious that the highest resistivity (i.e. lowest conductivity) is obtained for PVD-250 among all samples. The lowest measured value of resistivity in the present study $(2.2 \mu \Omega \cdot \mathrm{cm})$, is attributed to the PVD-400 film and is $30 \%$ higher than that of bulk copper $(1.67 \mu \Omega \cdot \mathrm{cm})[9]$. In the literature, a lot of studies focus on the evolution of copper microstructure as function of the deposition method and its process parameters variations, especially for DC magnetron sputtering. Studies on the resistivity evolution as function of film thickness or process parameters are also found $[5,18,23,24,37,38]$. However, crystallite size and/or crystallinity and film texture are not always specified. A summary diagram of resistivity data as function of the crystallite size and the deposit technique is reported in Fig. $3[5,22,23,37-43]$. Resistivity values for very thin films obtained by thermal evaporation [39], using electroplating [41] and electroless plating [42] are also reported. It is well-known that the copper film resistivity is close or higher than the bulk resistivity and increases with decreasing film thickness for magnetron sputtering $[5,23,42]$.

\subsection{Discussion}

As the thickness increases, coalescence and growth of crystallites occur, resulting in the decrease of the defect density. It is well-known that the increase of resistivity is due to various additional phenomena such as scattering from defects (vacancies, dislocations, grain boundaries) and non-specular scattering from the free surface, bottom interface and side-wall interfaces of the films. Electron mean path is reduced, leading to an increase in resistivity. Crystallite size plays a key role for a polycrystalline film because defects concentration is proportional to the number of crystallite boundaries and the defects associated with each crystallite boundary [44] which act as trap centers. When the film thickness is decreased, the crystallite size decreased [5] as well as the mobility of charge carriers. Presence of a significant amount of amorphous phase (when films are not well crystallized), results in a broadening of the crystallite boundaries which increase the energy barrier height across the crystallite boundaries according to the Slater theory [45]. Effect of annealing is beneficial to reduce resistivity thanks to a decrease of the defect concentration and increase of crystallinity. Process parameter modification such as the argon pressure used during deposition leads to the same conclusion. An increase of the argon pressure causes a decrease in both average energy of reflected $\mathrm{Ar}$ atoms and the ratio of energetic $\mathrm{Ar}$ to $\mathrm{Cu}$ atoms as an increase in deposition rate, reducing grain size and improving resistivity (up to 16 times for [38]). Comparing our results to the study of Qiu et al. [38] where similar deposition rate and Ar pressure for DC magnetron sputtering were used, different texture coefficients $\left(\mathrm{TC}_{(111)}=1.21, \mathrm{TC}_{(200)}=0.75\right.$ and $\left.\mathrm{TC}_{(220)}=1.04\right)$ are obtained for a similar film thickness. It is obvious than texture and therefore defect presence in the film impact the resistivity. Mech et al. [23] explained the higher bulk resistivity of sputtered films as a result of either internal stress or large quantity of dislocation in deposited films and the benefic effect for resistivity values of an increase of the film thickness (resistivity is inversely proportional to film thickness until $250 \mathrm{~nm}$ for copper [23] and then it remains constant). Dislocations increase the resistivity at a rate of $10^{-11}$ $10^{-13} \mu \Omega \cdot \mathrm{cm}$ per area density of dislocation lines $/ \mathrm{cm}^{2}$ depending on their type and orientation [46]. In their study, the crystallite size and the roughness are tuned with process parameters. It was demonstrated that high crystallinity leads to low resistivity $(1.86 \mu \Omega \cdot \mathrm{cm}$ for $70 \mathrm{~nm}$ crystallite size) even if roughness is increased. The reduction of the resistivity compared from PVD-400 to PVD-250 is in agreement with an increase of crystallite size, crystallinity and $\mathrm{TC}_{(111)}$. The difference with bulk copper resistivity can be explained in part by the crystallinity value.

Bahlawane et al. [47] also showed that the copper film resistivity increases with decreasing thickness for film prepared by CVD. Without specifying the crystallite size, some authors [22,48] announced that a chemical/supercritical fluid chemical deposition (CFD/SFCD) process, which enables precursor concentration far above ranges in CVD, yielded $50 \mathrm{~nm}$ thick films, exhibiting near-bulk resistivity.

In this study, a resistivity of $8 \mu \Omega \cdot \mathrm{cm}$ for a crystallite size of $87 \mathrm{~nm}$, a crystallinity of $33 \%$ and a uniform strain value of $-0.14 \%$ was determined for the sample prepared at $250{ }^{\circ} \mathrm{C}$ via SFCD. After annealing, a significant decrease of the resistivity value is observed $(4.7 \mu \Omega \cdot \mathrm{cm}$ ) combined to an increase of the crystallinity (up to $60.2 \%$ ) and a decrease of the uniform strain value $(-0.05 \%)$. All these observations are in agreement with results observed for magnetron sputtering. The purity of the SFCDs deposited films is little affected by residual contamination coming from the thermal decomposition of $\mathrm{Cu}$ precursor $\left[\mathrm{Cu}(\mathrm{tmhd})_{2}\right]$ in $\mathrm{scCO}_{2}$ such as carbon and oxygen when $\mathrm{H}_{2}$ is used 
as reducing agent [22]. Only the increase of crystallinity can explain this evolution highlighting the beneficial effect of annealing for SFCD films in order to improve their electrical properties without significant changes of microstructure.

\section{Conclusions}

Based on the study of the crystallite size, the crystallinity, the texture and the uniform strain, grain size, purity and microstructure, comparison of the evolution of electrical properties is done for RF magnetron sputtered copper films and supercritical fluid deposition with $\mathrm{H}_{2}$ as reducing agent. A preferential (111) orientation is noticed for all the films deposited on an AIN substrate independently of the technique used for the selected parameters. Based on literature, a diagram (Fig. 3) showing relevant resistivity data as function of the crystallite size and the deposit technique is reported (non-exhaustive list which includes this study). Our results for the SFCD technique confirm its viability to produce nanostructured copper thin films with low resistivity values. An additional annealing of the SFCD films leads to no significant changes in microstructure except for an increase of the film crystallinity with as consequence the resistivity value reduction.

\section{References}

1. D.C. Edelstein, G.A. Sai-Halasz, Y.J. Mii. VLSI on-chip interconnection performance simulations and measurements. IBM J. Res. Dev., 39 (1995), pp. 383-401.

2. P.L. Pai, C.H. Ting. Copper as the future interconnection materials. Proceedings of the Sixth International IEEE VLSI Multilevel Interconnection Conference (1989), pp. 258-264.

3. S.P. Murarka. Multilevel interconnections for ULSI and GSI era. Mater. Sci. Eng., R19 (1997), pp. 87-151.

4. B. Yu, P. Woo, U. Erb. Corrosion behaviour of nanocrystalline copper foil in sodium hydroxide solution. Scr. Mater., 56 (2007), pp. 353-356.

5. S.K. Mukherjee, L. Joshi, P.K. Barhai. A comparative study of nanocrystalline Cu film deposited using anodic vacuum arc and dc magnetron sputtering. Surf. Coat. Technol., 205 (2011), pp. 4582-4595.

6. R.K. Aithal, S. Yenamandra, R.A. Gunasekaran, P. Coane, K. Varahramyan. Electroless copper deposition on silicon with titanium seed layer. Mater. Chem. Phys., 98 (2006), pp. 95-102.

7. C.-E. Ho, C.-C. Chen, M.-K. Lu, Y.-W. Lee, Y.-S. Wu. In-situ study on the self-annealing behavior of electroplated Cu through the cantilever method, XRD, and EBSD. Surf. Coat. Technol., 303 (2016), pp. 86-93.

8. D.-W. Lee, O.-Y. Kwon, W.-J. Cho, J.-K. Song, Y.-N. Kim. Characteristics and mechanism of Cu films fabricated at room temperature by aerosol deposition. Nanoscale Res. Lett., 11 (2016), pp. 162-169.

9. R.A. Matula. Electrical resistivity of copper, gold, palladium ad silver. J. Phys. Chem. Ref. Data, 8 (1979), pp. $1147-1298$.

10. A. O'Neil, J.J. Watkins. Fabrication of device nanostructures using supercritical fluids. MRS Bull., 30 (2005), pp. $967-975$.

11. A.H. Romang, J.J. Watkins. Supercritical fluids for the fabrication of semiconductor devices: emerging or missed opportunities? Chem. Rev., 110 (2010), pp. 459-478.

12. M. Majimel, S. Marre, E. Garrido, C. Aymonier. Supercritical fluid chemical deposition as an alternative process to CVD for the surface modification of materials. Chem. Vap. Depos., 17 (2011), pp. 342-352.

13. C. Erkey. Preparation of metallic supported nanoparticles and films using supercritical fluid deposition. J. Supercrit. Fluids, 47 (2009), pp. 517-522.

14. C.F. Karanikas, J.J. Watkins. Kinetics of the ruthenium thin film deposition from supercritical carbon dioxide by the hydrogen

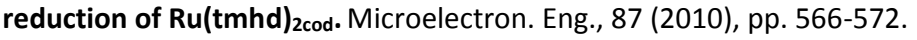

15. J.J. Watkins, J.M. Blackburn, T.J. McCarthy. Chemical fluid deposition: reactive deposition of platinum metal from carbon dioxide solution. Chem. Mater., 11 (1999), pp. 213-215.

16. J.J. Watkins, T.J. McCarthy. Polymer/metal nanocomposite synthesis in supercritical $\mathbf{C O}_{2}$. Chem. Mater., 7 (1995), pp. 199119940

17. E.T. Hunde, J.J. Watkins. Reactive deposition of cobalt and nickel films from their metallocenes in supercritical carbon dioxide solution. Chem. Mater., 16 (2004), pp. 498-503.

18. J.-H. Boo, M.J. Jung, H.K. Park, K.H. Nam, J.G. Han. High-rate deposition of copper thin films using newly designed high-power magnetron sputtering source. Surf. Coat. Technol., 188-189 (2004), pp. 721-727.

19. C.V. Thompson. Coarsening of particles on a planar substrate - interface energy anisotropy and application to grain-growth in thin films. Acta Metall., 36 (1988), pp. 2929-2934.

20. Z.P. Bazant, Z. Guo, H.D. Espinosa, Y. Zhu, B. Peng. Epitaxially influenced boundary layer model for size effect in thin metallic films. J. Appl. Phys., 97 (2005), Article 073506.

21. C.S. Barret, T.B. Massalski. Structure of Metals. Pergamon Press, Oxford, UK (1980). 
22. A. Cabanas, X. Shan, J.J. Watkins. Alcohol-assisted deposition of copper films from supercritical carbon dioxide. Chem. Mater., 15 (2003), pp. 2910-2916.

23. K. Mech, R. Kowalik, P. Zabinski. Cu thin films deposited by DC magnetron sputtering for contact surfaces on electronic components. Arch. Metall. Mater., 56 (2011), pp. 903-908.

24. B.H. Wu, J. Wu, F. Jiang, D.L. Ma, C.Z. Chen, H. Sun, Y.X. Leng, N. Huang. Plasma characteristics and properties of Cu films prepared by high power pulsed magnetron sputtering. Vacuum, 135 (2017), pp. 93-100.

25. M. Yu, J. Zhang, D. Li, Q. Meng, W. Li, M. Yu, J. Zhang, D. Li, Q. Meng, W. Li. Internal stress and adhesion of Cu film/Si prepared by both MEVVA and IBAD. Surf. Coat. Technol., 201 (2006), pp. 1243-1249.

26. X. Zhang, K.N. Tu, Z. Chen, Y.K. Tan, C.C. Wong, S.G. Mhaisalkar, X.M. Li, C.H. Tung, C.K. Cheng. Pulse electroplating of copper film: a study of process and microstructure. J. Nanosci. Nanotechnol., 8 (2008), pp. 2568-2574.

27. N. Alshwawreh, M. Militzer, D. Bizzotto, J.C. Kuo. Resistivity-microstructure correlation of self-annealed electrodeposited copper thin films. Microelectron. Eng., 95 (2012), pp. 26-33.

28. L. Aloui, V. Krisuyk, N. Prud'homme, B. Sarapata, F. Senocq, D. Samélor, C. Vahlas. CVD of pure copper films from amidinate precursor. ECS Trans., 25 (8) (2009), pp. 581-586.

29. P. Pokorny, J. Musil, P. Fitl, M. Novotny, J. Lancok, J. Bulir. Contamination of magnetron sputtered metallic films by oxygen from residual atmosphere in deposition chamber. Plasma Process. Polym., 12 (2015), pp. 416-421.

30. S. Junaid, S. Qazi, A.R. Rennie, J.K. Cockcroft, M. Vickers. Use of wide-angle X-ray diffraction to measure shape and size of dispersed colloid particles. J. Colloid Interface Sci., 338 (2009), pp. 105-110.

31. S. Simões, R. Calinas, M.T. Vieira, M.F. Vieira, P.J. Ferreira. TEM and SEM in-situ annealing of nanocrystalline copper thin films. Nanotechnology, 21 (2010), pp. 1-12.

32. T.H. De Keijser, J.I. Langford, E.J. Mittemeijer, A.B.P. VogelsUse of the Voigt in a single-line method for the analysis of X-ray diffraction line broadening. J. Appl. Crystallogr., 15 (1982), pp. 308-314.

33. S. Du, Y. LiEffect of annealing on microstructure and mechanical properties of magnetron sputtered Cu thin films. Adv. Mater. Sci. Eng., 451 (2015), p. 969580.

34. M.M. Ling, Z. BaoThin film deposition, patterning, and printing in organic thin film transistors. Chem. Mater., 16 (2004), pp. 4824-4840.

35. K.-Y. Chan, B.-S. TeoAtomic force microscopy (AFM) and X-ray diffraction (XRD) investigations of copper thin films prepared by dc magnetron sputtering technique. Microelectron. J., 37 (2006), pp. 1064-1071.

36. K.-Y. Chan, T.-Y. Tou, B.-S. TeoEffects of substrate temperature on electrical and structural properties of copper thin films. Microelectron. J., 37 (2006), pp. 930-937.

37. M.-T. Le, Y.-U. Sohn, J.-W. Lim, G.-S. ChoiEffect of sputtering power on the nucleation and growth of cu films deposited by magnetron sputtering. Mater. Trans., 51 (2010), pp. 116-120

38. H. Qiu, F. Wang, P. Wu, L. Pan, Y. TianStructural and electrical properties of Cu films deposited on glass by DC magnetron sputtering. Vacuum, 66 (2002), pp. 447-452.

39. H.-D. Liu, Y.-P. Zhao, G. Ramanath, S.P. Murarka, G.-C. WangThickness dependent electrical resistivity of ultrathin (< 40 nm) Cu films. Thin Solid Films, 384 (2001), pp. 151-156.

40. V. Krisyuk, L. Aloui, N. Prud'homme, S. Sysoev, F. Senocq, D. Samélor, C. VahlasCVD of pure copper films from amidinate precursor electrochemical/chemical deposition and etching. Electrochem. Solid-State Lett., 14 (3) (2011), pp. D26-D29.

41. T. Hara, Y. Shimura, K. NamikiResistivity of thin copper interconnection layers. Jpn. J. Appl. Phys., 44 (13) (2005), pp. L408-L411.

42. X. Cui, D.A. Hutt, P.P. ConwayEvolution of microstructure and electrical conductivity of electroless copper deposits on a glass substrate. Thin Solid Films, 520 (2012), pp. 6095-6099.

43. E. Kondoh, T. Ueno, S. Kurita, M. Watanabe, S. Yamamoto, T. Suemasu. Supercritical $\mathrm{CO}_{2}$ reactor for wafer-scale thin film deposition: reactor concept, numerical results, and Cu deposition. J. Supercrit. Fluids, 104 (2015), pp. $49-53$.

44. K.L. Chopra. Thin Film Phenomena. Robert E Krieger, Huntington (1979).

45. J.C. Slater. Barrier theory of the photoconductivity of lead sulfide. Phys. Rev., 103 (1956), pp. 1631-1644.

46. K. Schröder. Handbook of Electrical Resistivities of Binary Metallic Alloys, CRC Handbook, Cleveland (1983).

47. N. Bahlawane, P.A. Premkumar, F. Reilmann, K. Kohse-Höinghaus, J. Wang, F. Qi, B. Gehl, M. Bäumer. CVD of conducting ultrathin copper films. J. Electrochem. Soc., 156 (2009), pp. D452-D455.

48. T. Momose, M. Sugiyama, Y. Shimogaki. Precursor evaluation for Cu-supercritical fluid deposition based on adhesion properties and surface morphology. Jpn. J. Appl. Phys., 44 (2005), pp. L1199-L1202. 


\section{Table 1}

Film thickness estimated on cross-section SEM images, crystallite sizes (values based on broadening of 111 Bragg reflection) and degree of crystallinity derived from XRD data for PVD and SFCD copper films.

\begin{tabular}{llll}
\hline Sample & Film thickness $(\mathrm{nm})$ & Average crystallite size $(\mathrm{nm})$ & Xc $(\%)$ \\
\hline PVD-250 & $532 \pm 15$ & $10 \pm 3$ & 14 \\
PVD-400 & $596 \pm 32$ & $123 \pm 7$ & 27 \\
SFCD-250 & $554 \pm 28$ & $87 \pm 7$ & 33 \\
SFCD-400 & $550 \pm 25$ & $116 \pm 8$ & 60 \\
\hline
\end{tabular}

\section{Table 2}

Variations in copper lattice parameter (a) and uniform strain measurement ( $\varepsilon$ ) for SFCD (SFCD-250 and SFCD-400 which is annealed) and magnetron sputtered (PVD-250 and PVD400) samples.

\begin{tabular}{lll}
\hline Sample & $\mathrm{a}(\AA)$ & $\varepsilon(\%)$ \\
\hline PVD-250 & 3.599 & -0.48 \\
PVD-400 & 3.601 & -0.43 \\
SFCD-250 & 3.611 & -0.14 \\
SFCD-400 & 3.614 & -0.05 \\
\hline
\end{tabular}




\section{Table 3}

Film thickness and surface roughness (average surface roughness $R_{a}$ and total height of the roughness profile $\mathrm{R}_{\mathrm{t}}$ ) of the copper as-deposited films as a function of the technique.

\begin{tabular}{llll}
\hline Sample & Film thickness by SEM $(\mathrm{nm})$ & \multicolumn{2}{l}{ Surface roughness } \\
\cline { 3 - 4 } & & $\mathrm{R}_{\mathrm{a}}(\mathrm{nm})$ & $\mathrm{R}_{\mathrm{t}}(\mathrm{nm})$ \\
\hline PVD-250 & $532 \pm 15$ & $43 \pm 12$ & $460 \pm 142$ \\
PVD-400 & $596 \pm 32$ & $82 \pm 8$ & $780 \pm 52$ \\
SFCD-250 & $554 \pm 28$ & $34 \pm 5$ & $240 \pm 24$ \\
SFCD-400 & $550 \pm 25$ & $40 \pm 10$ & $190 \pm 35$ \\
\hline
\end{tabular}

\section{Table 4}

Copper electrical conductivity and resistivity values measured at room temperature using 4-point probe method for SFCD (SFCD-250 and SFCD-400 which is annealed) and magnetron sputtered (PVD-250 and PVD400) samples.

\begin{tabular}{lll}
\hline Sample & Electrical conductivity $\left(\mathrm{MS} \mathrm{m}^{-1}\right)$ & Resistivity $(\mu \Omega \cdot \mathrm{cm})$ \\
\hline PVD-250 & $2.6 \pm 0.9$ & 38.4 \\
PVD-400 & $47.1 \pm 3.1$ & 2.2 \\
SFCD-250 & $21.1 \pm 4.0$ & 8.0 \\
SFCD-400 & $37.2 \pm 2$ & 4.7 \\
\hline
\end{tabular}




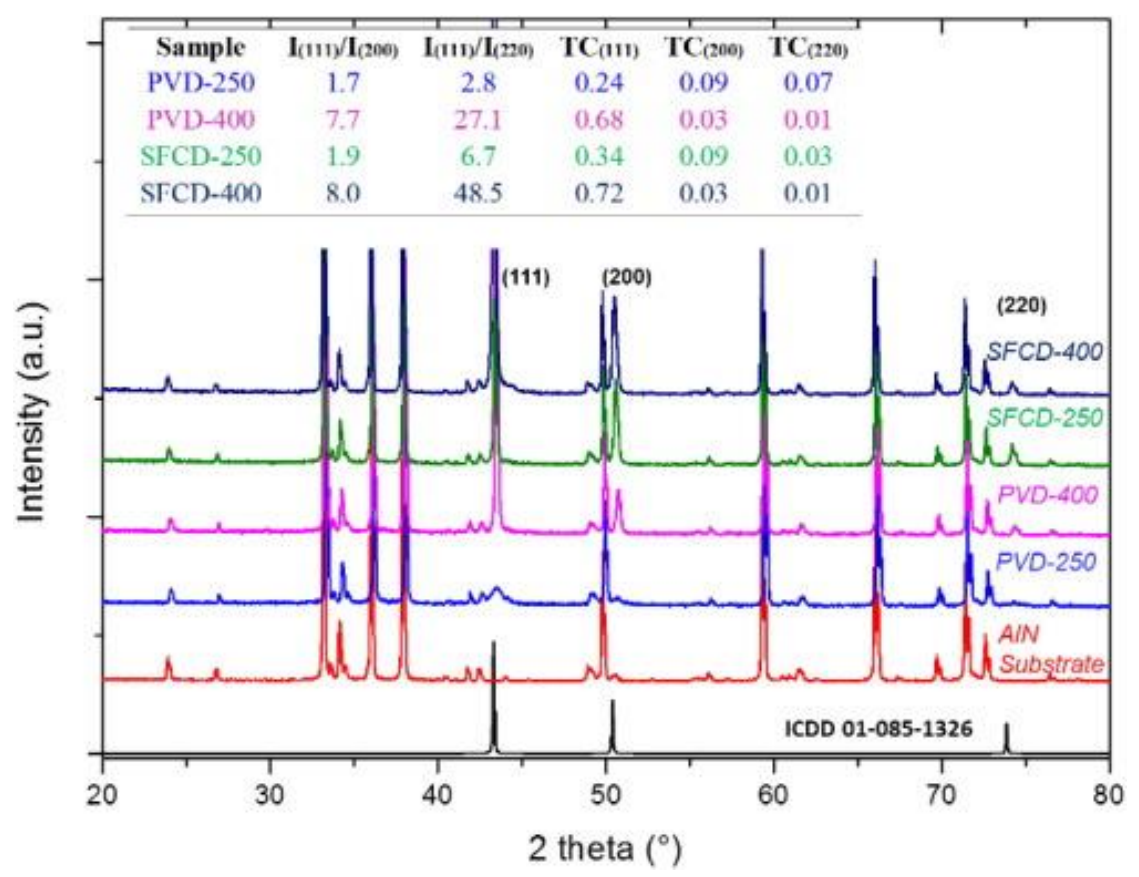

Fig. 1. XRD patterns of AIN substrate and Cu films. (hkl) Indexes correspond to copper (JCPDS 04-0836). Calculation of the $I_{(111)} / I_{(200)}$ and $I_{(111)} / I_{(220)}$ peak intensity ratios and $\mathrm{TC}_{(111)}, \mathrm{TC}_{(200)}$ and $\mathrm{TC}_{(220)}$ texture coefficients for SFCD (SFCD-250 and SFCD-400 which is annealed) and magnetron sputtered (PVD-250 and PVD400) samples.
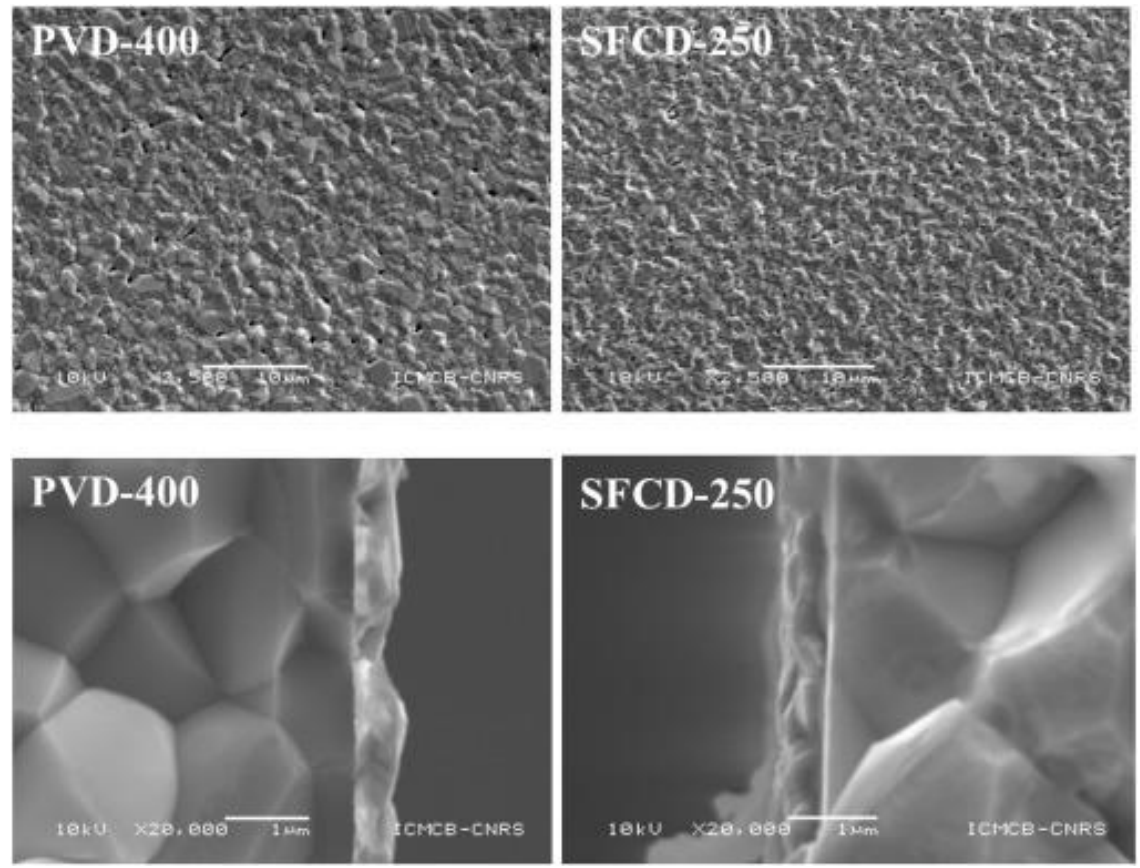

Fig. 2. SEM micrographs of cross-section and surface morphology of SFCD-250 and PVD-400 copper films. 


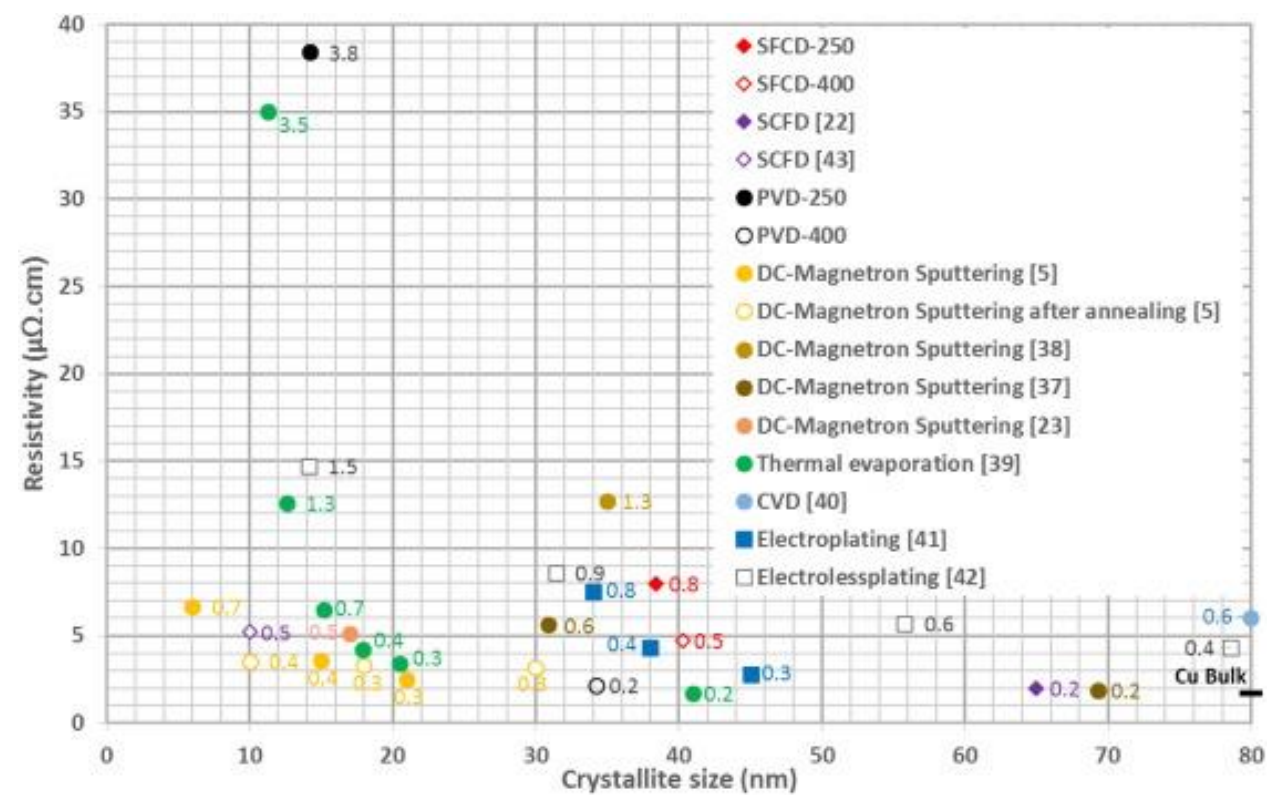

Fig. 3. Resistivity of copper films as function of the crystallite size and the deposition technique (this study and $[5,22,23,37-43])$. 